\title{
Tools for Sustainable Product Design: Additive Manufacturing
}

\author{
Olaf Diegel (Corresponding author), Sarat Singamneni, Stephen Reay \& Andrew Withell \\ Centre for Rapid Product Development \\ Faculty of Design and Creative Technologies, Auckland University of Technology \\ Room WS117, 34 St Paul St., Auckland, New Zealand \\ Tel: 64-9-921 $9485 \quad$ Fax: 64-9-921 $0421 \quad$ E-mail: olaf.diegel@aut.ac.nz
}

\begin{abstract}
The advent of additive manufacturing technologies presents a number of opportunities that have the potential to greatly benefit designers, and contribute to the sustainability of products. Additive manufacturing technologies have removed many of the manufacturing restrictions that may previously have compromised a designer's ability to make the product they imagined. Products can also be extensively customized to the user thus, once again, potentially increasing their desirability, pleasure and attachment and therefore their longevity. As additive manufacturing technologies evolve, and more new materials become available, and multiple material technologies are further developed, the field of product design has the potential to greatly change.
\end{abstract}

This paper examines how aspects of additive manufacturing, from a sustainable design perspective, could become a useful tool in the arsenal to bring about the sustainable design of consumer products.

Keywords: Sustainable product design, Additive manufacturing, Design quality, Mass customization

\section{Introduction}

The past decade has seen a surge in awareness for environmental conservation and the preservation of the earth's natural resources and environment. Sustainability is rapidly emerging as an issue that designers and engineers must engage with and embrace to survive in a more sustainability conscious world. Indeed, sustainability is now taught as an integral part of many design and engineering degrees, recognising the growing acceptance of the role sustainability has to play in the development of our futures. Yet, on examining what is meant by 'sustainable' products, a plethora of definitions and methodologies emerge, some of which contain omissions or contradict each other. This confusion means that sustainability often gets relegated to being just a buzz-word used on marketing material no matter how sustainable, or not, a product actually is. Part of the challenge for design and designers is to move beyond the "hype" and to engage in design activities with the level of integrity that our futures deserve.

Design practitioners, through their roles in shaping the future, are viewed as being able to promote change in society, especially around unsustainable behaviours (Sosa \& Gero 2008). This thinking is not new and has been promoted at various levels for many years. In "Design for society", Whiteley (1993) argues that designers have a moral and ethical obligation to be responsible for their designs, and the social and environmental impacts of their work. Whiteley (1993) follows the writings of others (i.e. Papanek 1985) to reveal a lack of values and ambition, in the juxtaposition between design and consumerism. Consumer-led design is so prevalent that it appears as a "natural and inevitable aspect of our society" (Whiteley 1993, p7). For design to change, the role and values of design, as well as the relationship of design with society, needs to change. This may come from a reflection as to whether design is merely a servant of industry, or can inform through intelligent thought and action, while contributing to the global ecological balance (Whiteley 1993).

The design community is consequently in a state of transformation. Designers have responded to the growing issues around social and environmental issues by developing concepts and frameworks such as eco-design and sustainable design, and numerous related iterations (Sherwin 2004). These concepts are centered on ideals of acknowledging ecological limits and demonstrating responsibility, and increased contribution to society and the environment (Sherwin 2004). Within the context of product design, approaches to sustainability generally fall in between two broad areas: eco-design and sustainable design (Tischner \& Charter, 2001, Sherwin, 2004). While these methods are essential and incredibly helpful to guide designers through the process of designing sustainable products, they do not explore or capture the potential for new and developing technologies to help support the product development process. Many sustainable design attempts appear to be "one-off" or experimental designs. While this process is an essential part of the development towards understanding the role of design in developing true sustainability, it also demonstrates the uncertainty surrounding how the principles of sustainability can be successfully incorporated into mass-produced everyday consumer items.

Of the world's nearly 7 billion population, about 1.7 billion people now belong to the "consumer class" (Halweil et al., 2004) with lifestyles devoted to the accumulation of non-essential goods, characterized by a desire for bigger houses, more cars and more consumer goods. Nearly half of these global consumers reside in developing countries. There are 240 million consumers in China and 120 million in India and these are the markets with the greatest potential for growth. 
In the context of environmental sustainability, the consumerist's "throw away" mentality has had a hugely detrimental effect on the planet, in terms of increasing levels of pollution and degraded natural habitats and ecosystems. This throw away mentality extends from disposable lighters, to cameras, to other cheaply made goods with built in product-obsolescence that have little consumer attachment.

Planned obsolescence (Packard, 1978), or built-in obsolescence, is the process of a product purposefully becoming obsolete or non-functional after a certain period of use in a way that is planned or designed by the manufacturer. Planned obsolescence has potential economic benefits for the producer because the product fails and the consumer is under continual pressure to repurchase. Design for disposal encourages throwing away sophisticated and energy-expensive items. Some brands of inkjet printers, for example, incorporate the print head technology within the cartridge so that it must be discarded when the ink container is empty. The conflict between profits and design objectives is apparent. The fear of market saturation seemed to require such methods to ensure a prosperous economy, yet the consumer is being sold inferior products that could have been made more durable at little extra cost.

Today there are, quite sadly, too few products that are not designed with planned obsolescence in mind. It is evident that planned obsolescence and environmental sustainability are in almost direct conflict. Though drastic changes in consumer culture are beyond the scope of this paper, designers can certainly play a role in designing products that go beyond planned obsolescence.

\subsection{Sustainable Product Design}

Sustainable product design incorporates economic imperatives, ethics and other socio-economic dimensions of sustainability, and uses ecological principles as methods of designing, thus aiming for "triple bottom-line" solutions (Tischner \& Charter, 2001, Sherwin, 2004). Triple bottom-line, as shown in figure 1, divides sustainability into three areas: environmental, economic and social sustainability. An ideal product is one which maximizes all three areas in that it is good for the environment, is profitable for the company and improves society.

Economic sustainability is relatively easy to measure as it is, to a large degree, easy to quantify. Social sustainability is somewhat more difficult to measure because of the intangible nature, and the subjectivity, of many of the factors that are deemed of benefit to society. Environmental sustainability, from a product point of view, is also difficult to quantify as, to get a true understanding of a products' impact, one has to look at the entire life-cycle of the product which can become quite a complex endeavour. This has led to the development of a variety of tools and methodologies, such as cradle-to-grave, cradle-to-cradle, and Life-Cycle Analysis in an attempt to better quantify the environmental impact of products. Even using statements such as "good for the environment", as used in the ideal product description above, can be misleading. There are few, if any, existing hardware products that, if one analyzes them from cradle to cradle, have a positive impact on the environment (Zafarmand et al. 2003, Sherwin 2004). It could therefore be said that part of the role of the 'sustainable' product designer is to design products that, while maximizing their economic and social impact, minimize their harmful effects on the environment.

As sustainable design is a relatively new discipline, there are currently few models for implementing it in practical product design projects (Tischner \& Charter, 2001). As an attempt to resolve the natural tensions between the three areas described above the literature on sustainable design presents some common models to help in the management of sustainable product design. It should be noted, however, that all these models tend to focus on environmental and economic issues and few attempt to address the wider social and ethical issues of the product (Tischner \& Charter, 2001), and none of them address design quality as a factor that affects the longevity of a product, and therefore its sustainability.

In the case of this paper we define sustainable design as design which aims to achieve triple-bottom line ideals by striving to produce products that minimize their detriment to the environment while, at the same time, achieving acceptable economic benefits to the company and, wherever possible, having a positive impact on society.

\section{The Relationship between Design Quality and Sustainability}

It should be noted that the bulk of the literature on sustainable product design tends to focus on the technicalities of lowering the environmental impacts of material, resource and energy use. According to van Nes \& Cramer (2003) and Vincent (2006), very little of this literature deals with 'design quality' as a factor in improving product longevity. By longevity we mean extending the useful life of a product, and therefore reducing the impact it has on the environment. Though there is a large quantity of literature on various aspects of design quality, and even on its importance to sustainability, there is little that states how it fits into the methodologies towards attaining sustainable product design (van Nes, \& Cramer, 2005, Park, 2005).

'Design quality' is difficult to define as it is an area that is often regarded as subjective (Kemp \& Martens, 2007). If one examines quality from a sustainable product point of view, it could be argued that design quality has a direct effect on the longevity of a product (van Nes, \& Cramer, 2005, Vincent, 2006). Here we use design quality not just to mean the 'technical quality' of a product but also the less tangible 'desirability' of a product, 'pleasure 
of use' of a product, as well as the 'attachment' of a user to a product. Designers can stimulate desirability, increase pleasure and deepen attachment by designing products that not only function better, are more aesthetically pleasing than comparable products, but are also tailored to better suit the individual needs of the user. Govers and Mugge, 2004 argue that if an object is highly desirable its longevity is extended, and its negative impact on the environment is therefore reduced.

One could extend this argument to say that products which are so well designed that they become lasting 'objects of desire, pleasure and attachment' are more sustainable because they do not get disposed of in the way that lower quality designed products do. From this, one could argue that the E-type Jaguar, for example, is potentially more environmentally sustainable than a modern hybrid car because, if one looks at its complete life-cycle, it performs superbly. This is because the quality of its design makes it such a great object of desire that it never gets scrapped as a conventional car possibly would. It is cherished by its owner, with great care being taken in its maintenance and, in all likelihood, could last for several generations.

So how can designers improve desirability, increase pleasure, and deepen product attachment to extend product life and thus improve product sustainability? There are at least two current design factors that may have a negative effect on design quality and thus product longevity.

The first is manufacturing-design compromise. Because of the restrictive ways in which products currently need to be manufactured, a designers' original design vision has to be compromised to the extent that the product can be made. This means that the product may, potentially, lose some of the desirability the originally envisioned design may have had (Hernandez and Mistree 2000).

The other factor is that, because of current manufacturing technologies, products are mass-manufactured as one-size-fits-all products that, because of their generic nature, are compromised so as to be useable by all customers but ideal for none (Hunt, 2006).

Additive manufacturing is a relatively recent form of manufacturing that has the potential to address both of these factors, and thus has great potential as an effective tool for more sustainable product design.

\section{Additive Manufacturing}

The Society of Manufacturing Engineers defines Additive Manufacturing (AM) as the process of manufacturing a physical object through the layer-by-layer selective fusion, sintering or polymerization of a material (SME, 2010). The additive manufacturing process begins by taking a $3 \mathrm{D}$ computer generated file and slicing it into thin slices (commonly ranging from $0.01 \mathrm{~mm}$ to $0.25 \mathrm{~mm}$ per slice depending on the technology used). The additive manufacturing machine then builds the model one slice at a time, with each subsequent slice being built directly on the previous one, as shown in figure 2. As a result of the material deposition and processing operations, the digital electronic model is converted into a physical part or product.

Several different additive manufacturing technologies exist, which differ mainly in terms of the materials they use to build the part, which are typically in a powder, filament, or liquid raw state, and the process used for creating the model slices. Until recently, many of these technologies, such as stereolithography (SLA), Fused Deposition Modelling (FDM), early Selective Laser Sintering (SLS) systems and 3D printing, were only able to make parts for prototyping purposes, as the processes produced parts that were not as strong as injection moulded plastic or cast metal parts (Hopkinson et al, 2006). The latest generation of additive manufacturing technologies, however, now allow full-strength polymer and metal parts to be produced within hours rather than days (Wohlers, 2009).

The main technologies that can, today, be classified as rapid manufacturing technologies (as opposed to rapid prototyping) are Selective Laser Sintering (SLS), Selective Laser Melting (SLM) and Electron Beam Melting (EBM). These technologies create the part by spreading a very thin (typically less than $0.1 \mathrm{~mm}$ ) layer of powdered material, and then selectively fusing the powder for the appropriate parts of the digital slice of the model. Another layer of powder is then spread on top of the previous one and that is again selectively fused for that slice of the model and, at the same time, fused to the layer beneath it. SLS/SLM uses a laser beam for the fusing operation, while EBM uses an electron beam to melt the material. The un-melted powder acts a as a support material for all the layers above it.

Unlike subtractive manufacturing, where material is removed from a larger block of material until the final product is achieved, most additive manufacturing processes do not yield excessive waste material. As the part is made from material in a powder or liquid form, whatever powder or liquid does not get hardened by the process gets reused for the subsequent parts. Additive manufacturing typically also does not require the large amounts of time needed to remove unwanted material, consequently reducing time and costs, and producing very little waste (Wohlers, 2009).

It is only over the last few years that additive manufacturing is being used by more and more companies as a viable production technology. Companies such as Adler Ortho (Italy) are using additive manufacturing technologies as their main production process for manufacturing titanium hip implants. As new polymer and 
metal materials are developed and the speed and precision of the machines further increase, more additive manufacturing machines are likely to find their way into mainstream production lines (Wohlers, 2009).

Additive manufacturing enables the creation of parts and products with complex features, which could not easily have been produced via subtractive or other traditional manufacturing processes. Injection moulded or die-cast parts, for example, must be removable from the die in which they are made and must therefore be designed in such a way that this can be done. The metal part shown in figure 3 , for example, could not easily be machined or cast because there is no way of removing the internal part of the die from the component or of machining the interior surfaces (EOS, 2010a). Additive manufacturing, however, does not suffer from these particular restrictions. The complexity of the part does not affect whether it can be made, or even its cost. It allows for components of almost any complexity, freedom in design and increased flexibility in the features and functions of the end product.

With additive manufacturing it is also possible to manufacture complex interlocked moving parts in ready-made working assemblies. Though two components may be permanently linked together, they are made as a single component and come out of the machine assembled and ready to work. Figure 4 shows a tie-down clamp made on an EOS laser sintering system out of aluminium filled polyamide material, which is composed of four different components that allow the clamp to operate in the correct way (EOS, 2010b). The entire clamp is, however, manufactured in a single operation with no assembly whatsoever required. If the clamp were to be manufactured using traditional manufacturing methods, it would require, at least, eight components and an assembly procedure to attach all the separate components together.

\subsection{Mass Customization}

With additive manufacturing parts can be immediately made as there is no longer a long lead-time to get tooling produced. This has a great impact on new product time to market, and on the ability to easily produce model changes throughout the life of a product. It also has implications in stock control: As components can be made on the spot, companies may no longer need to hold stock of spare parts as they simply manufacture the parts when needed.

From a product design perspective, it also means that every component made can be completely different to the others in a production run without significantly affecting the manufacturing cost. This opens the door to mass-customization in which, though mass-manufactured, each product can be customized to each individual customer. Pine and Gilmore (2000) present a framework of mass-customisation based on four approaches, Transparent, Collaborative, Adaptive and Cosmetic Customisation. For example with Adaptive Customisation 'standard goods and services can be easily tailored, modified, or reconfigured to suit each customer's needs' (Pine and Gilmore, 2000). When a patient orders a new product, their personalized data is acquired and is used to modify the basic design configuration to perfectly match their data. The customized components are then fabricated through additive manufacturing, and the customer ends up with a product customized to them.

The range of personalized data is, of course, enormous and can range from specific shape and size data to full digitized body scans and even MRI scans for internal organs or bones. Some excellent tools to acquire this data already exist (such as laser scanners, body scanners, MRI machines, etc.), and more are being developed as data acquisition technologies improve. Then there is all the personal taste data such as colour, texture, mode of use, and more, that all need to be acquired in order to further help with product customization.

For this new way of designing products to be used effectively the product design and the computer aided design industries will need to develop new methods for integrating personalized customer data into their designs. This development has already started, particularly in the hearing aid (EOS, 2010c) (figure 5) and the dental industries, in which specialized software exists to automate the processes from patient data acquisition to part production. This now needs to be extended to encompass others, including consumer product industries.

This ability to customize every product made has the potential to greatly affect the desirability, and therefore the longevity, of those products. Are customers not more likely to cherish and keep a product that has been specially customized to their particular needs? Though there is little quantifiable data to answer this question as mass-customization is still an emerging field, anecdotal data from the high-value custom-made products would seem to indicate that it is, indeed, the case (Mugge, et al, 2004).

\subsection{Freedom of Design}

Because of traditional manufacturing technology restrictions a product, which the designer may have originally envisioned as having a certain aesthetic and functionality, may need to be compromised so that it can be cost-effectively made. Most designers are quite accustomed to hearing the response of "it cannot be made like that" from manufacturing engineers. They may then need to compromise their design to the extent that the product loses the essence that truly embodies the designers' vision. If this becomes the case then one must ask if the product thereby becomes less desirable and therefore loses some of the longevity it may have had had it been able to be manufactured to the designer's original vision? 
With additive manufacturing, complexity and geometry no longer affect manufacturability. Almost anything the designer imagines can be made precisely as the designer conceived it (figure 6).

If one accepts that design practitioners, through their roles in shaping the future, are viewed as being able to promote change in society, especially around unsustainable behaviours (Sosa \& Gero, 2008), then one must conclude that the product designer is the person with the best ability to create true objects of desire. If that is the case, then giving them a tool such as additive manufacturing that allows them to materialize their vision is an absolute necessity. It bypasses the common problem of the design team being told by the manufacturing team that what they envisioned cannot be made.

\subsection{Additive Manufacturing Design Considerations}

It should be noted that additive manufacturing does not remove all manufacturing restrictions. It, instead, replaces them with a different set of design considerations that designers must take into account if they wish to successfully use the technologies. These new design considerations are, however, much easier for designers to both understand and comply with without them affecting design intent in a major way. Some of the principal design considerations to keep in mind when designing for additive manufacturing include:

- Enclosed voids: The components are built from powdered material, some of which is melted by the laser/electron beam, and the remainder of which acts as support material while the part is being built. If a part has a completely enclosed void, then there is no way to get the loose powder out of the void after the part is complete. If a hollow part is required, consideration should be give as to whether it is an acceptable compromise to have a small opening somewhere in the part through which the internal powder can be removed. If this is not an option then it may be better to do the part in two halves that can then be bonded or clipped together.

- Surface finish: As the process works by building up the model with flat layers, curves get converted into a series of steps, which can result in a visible 'stair-case' effect on horizontally sloping surfaces of the part. With SLS, the effect is not too severe except when dealing with gently sloping surfaces on which the effect can be visible. Consideration therefore needs to be given to face orientation and angle both when designing and when printing the part. These surface finish blemishes can also be relatively easily corrected through post-processing, such as rumbling, bead blasting, or sanding.

- Strength and flexibility: The part is built with each slice of the model being made in the horizontal ' $x-y$ ' orientation and the subsequent slices being added in the vertical ' $\mathrm{z}$ ' direction. This results in small variations in flexibility and strength between the vertical and horizontal orientation of the component. Though this is becoming much more homogenous on the more recent machines, due consideration should be given to the orientation in which the parts are printed to give the most favourable results. This is particularly relevant to living-hinges which need to be durable as they may be flexed many times.

- Machine and material costs: One important consideration when using additive manufacturing is the ratio of the value of the product versus the manufacturing quantity of the product. As a general rule, the cheaper the additive manufacturing machine, the more expensive the manufacturing material. In fact, for most of the lower cost machines, the material is so expensive that they can only be used for prototyping, rather than production. On the machines that can be classified as 'rapid manufacturing' machines, however, the material costs are beginning to approach a level that make them viable production processes. For a plastic SLS machine, capable of producing full strength parts, for example, the polyamide (nylon) powder costs around US\$70/Kg, making it viable for the production of parts for high value, low production components. The capital costs for these machines, is however, still prohibitive to the typical SME, so much of the production currently being undertaken with these machines is being done through service bureaus. The costs of machines is, however, reducing every year (Wohlers, 2009) gradually making them a realistic option for manufacturers to integrate into their production lines.

As additive manufacturing evolves, an entire new 'Design for Additive Manufacture' methodology will need to be developed to maximize the potential the technologies have to offer. Some work in this area has already begun with some researchers at Loughborough University proposing an online design for additive fabrication feature repository that helps designers to use the right technologies with the right feature designs (Campbell, R.I., 2008)

\section{Conclusions}

Sustainable product design is about creating products which, while maximizing their economic and social impacts, minimize any harmful effects they may have on the environment. One design philosophy which can help to achieve this is to strive towards designing products that become lasting objects of desire, and have a deep attachment between the product and user. Products that meet these criteria generally have a greatly increased lifespan, and this increased longevity reduces the products' negative impact on the environment.

Additive manufacturing, because it allows designers nearly unlimited freedom of design, and allows for mass-customization of consumer goods, offers the potential for creating such lasting objects of desire, pleasure, and attachment. Additive manufacturing is already beginning to be used in high-value medical products such as hearing aids, medical implants, and the aviation, automotive and marine industries. 
To use additive manufacturing to its maximum potential, designers will need to develop an appropriate set of design methodologies and rules to incorporate both the new features it allows and to take into account the new set of manufacturing restrictions it imposes.

Existing tools, such as Life Cycle Analysis, and design frameworks, such as cradle to cradle, will need to be adapted to fit the new paradigms of on-demand manufacturing and find ways of being applied earlier in the design process. Likewise, some of the frameworks about what constitute sustainability may need to be revised to better reflect the possibilities of advanced manufacturing technologies.

As additive manufacturing technologies continue to progress from rapid prototyping to manufacturing, more new materials become available, and multiple material technologies are developed to the point where complex multi-material production quality assemblies can be made, the field of product design will need to evolve in parallel so as to better meet the demands of emerging sustainable design trends.

\section{References}

Abukhader, S.M. (2008). Eco-Efficiency in the era of electronic commerce - Should an eco-effectiveness approach be adopted? Journal of Cleaner Production, 16: 801-808

Braungart, M., McDonough, W., Bollinger, A. (2007). Cradle to cradle design: creating healthy emission - a strategy for eco-effective product and system design. Journal of Cleaner Production, 15: 1337-1348

Campbell, R.I. (2008). Creating a Design for Additive Fabrication Feature Repository, RAPDASA 2008, Rapid Product Development Association of South Africa Conference, South Africa

Ciambrone, D.F. (1997). Environmental Life Cycle Analysis, CRC Press LLC, Florida, USA

EOS, (2010a), Available from http://www.eos.info/en/applications/aerospace.html, [Accessed February 2010]

EOS. (2010b). Available from http://www.eos.info/fileadmin/download/literature/EOSINT_P_760_E.pdf, [Accessed February 2010]

EOS. (2010c). Available from

http://www.eos.info/en/news-events/press-releases/pressdetails/select/pressemitteilungen/article/103/neues-paten t.html?tx_ttnews\%5Byear\%5D=2006\&tx_ttnews\%5Bmonth\%5D=11\&cHash=dbe63472b8, [Accessed February 2010]

EOS. (2010d). Available from http://www.eos.info/en/applications/target-plastic-parts/directpart-examples.html, [Accessed February 2010]

FOC (Freedom of Creation). (2010). Available from http://www.freedomofcreation.com/shop/order.php?cat=31, [Accessed February 2010]

Glavic, P., Lukman, R. (2007). Review of Sustainability terms and their definitions, Journal of Cleaner Production, 15: 1875-1885

Govers, P. C. M., and Mugge, R. (2004). 'I love my Jeep, because it's tough like me': The effect of product-personality congruence on product attachment, 2004 International Conference on Design and Emotion, Ankara, Turkey.

Grossman, B. (2010). Available from www.bathsheba.com, [Accessed February 2010]

Halweil, B., Mastny, L., Assadourian, E. (2004). State of the World 2004 - Special Focus: The Consumer Society, Worldwatch Institute, Washington DC.

Hernandez, G., Mistree, F. (2000). Integrating product design and manufacturing: a game theoretic approach, Engineering Optimization, Volume 32, Issue 62000 , pages $749-775$.

Hopkinson, N., Hague, R.J.M. and Dickens, P.M. (2006). Rapid Manufacturing an Industrial Revolution for the digital age, Wiley, 2006.

Hunt, D. (2006). PhD Thesis: A consumer perspective on mass customization, University of Missouri-Columbia, May 2006, Available from http://edt.missouri.edu/Winter2006/Dissertation/HuntD-052506-D4001/research.pdf, [Accessed February 2010].

Kemp, R., Martens, P. (2007). Sustainable development: how to manage something that is subjective and never can be achieved?, Sustainability: Science, Practice, \& Policy, 3(2):5-14.

Kobayashi, H. (2006). A systematic approach to eco-innovative product design based on life cycle planning, Advanced Engineering Informatics, 20: 113-125.

Ljunberg, L.Y. (2007). Materials selection and design for sustainable products, Materials and Design, 28: 466-479

McDonough, W., Braungart, M. (2002). Cradle to cradle: remaking the way we make things, North Point Press, New York, USA.

McDonough, W., Braungart, M., Anastas, P.T., Zimmerman, J.B. (2003). Applying the principles of green engineering to cradle-to-cradle design, Environmental Science and Technology, 1: 434-441. 
Mugge, R., Schifferstein, H. N. J. and Schoormans, J. P. L. (2004). Personalizing Product Appearance: The Effect on Product Attachment, 2004 International Conference on Design and Emotion, Ankara, Turkey.

Packard, V. (1978). Waste Makers, Simon \& Schuster, ISBN 0671822942.

Papanek, V. (1985). Design for the real world: human ecology and social change (2nd edition). Illinois, USA: Academy Chicago Publishers.

Park, M. (2005). Sustainable Consumption in the consumer electronics sector: Design solutions and strategies to minimise product obsolescence, 6th Asia Pacific Roundtable for Sustainable Consumption and Production (APRSCP); Melbourne, Australia, October 2005.

Pine, J \& Gilmore, J. (2000). Markets of one: Creating Customer-Unique value through mass customisation. Boston, USA: Harvard Business Review Book.

Sherwin, C. (2004) Design and Sustainability: A discussion paper based on personal experience and observations, The Journal of Sustainable Product Design, 4:21-31.

SME.

Available

from

http://www.sme.org/cgi-bin/communities.pl?/communities/techgroups/ddm/what_is_ddm.htm\&\&\&SME,

[Accessed February 2010]

Sosa, R and Gero, JS. (2008). Social structures that promote change in a complex world: the complementary roles of strangers and acquaintances in innovation. Futures 40:577-585.

Van Nes, N., and Cramer, J. (2003). Design strategies for the lifetime optimisation of products, The Journal of Sustainable Product Design, 3:101-107, Springer 2006.

van Nes, N., Cramer, J. (2005). Influencing product lifetime through product design, Business Strategy and the Environment, Volume 14 Issue 5, Pages 286 - 299.

Vincent, J. (2006). Emotional Attachment and Mobile Phones, Knowledge, Technology, \& Policy, Vol. 19, No. 1, pp. 39-44.

Wenzel, H., Hauschild, M., Alting, L. (1997). Environmental Assessment of Products. Volume 1, Chapman and Hall, London, UK.

Whiteley, N. (1993). Design for Society, Reaktion Books: London.

Wohlers, T. (2009). Worldwide progress report on the rapid prototyping, tooling, and manufacturing state of the industry, Wohlers Report 2009, Wohlers Associates, USA.

Tischner, U., Charter, M. (2001). Sustainable Product Design, pp118-138 in M. Charter and U. Tischner (eds), Sustainable Solutions: Developing products and services for the future, Greenleaf Publishing Limited, Sheffield, UK.

Zafarmand, S.J., Sugiyama, K. and Watanabe, M. (2003). Aesthetic and sustainability: the aesthetic attributes promoting product sustainability. The Journal of Sustainable Product Design 3: 173-186.

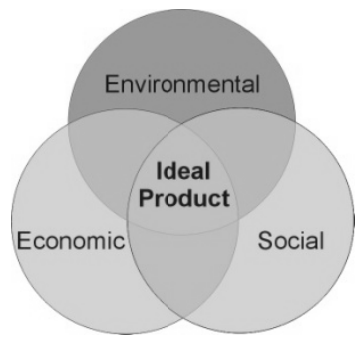

Figure 1. Triple Bottom-Line product design

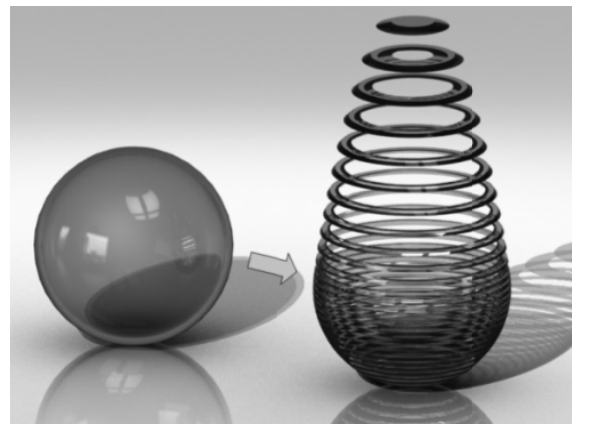

Figure 2. Additive manufacturing builds the part in a layer-upon-layer process 


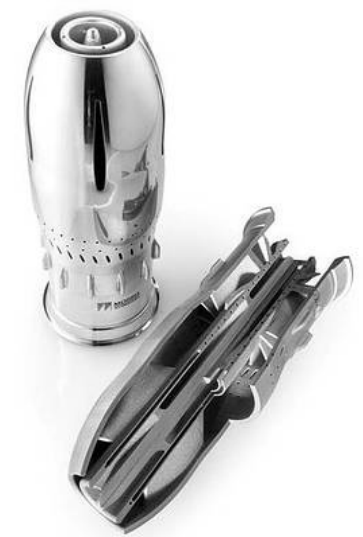

Figure 3. Fuel Injection Swirler (made out of Cobalt Chrome MP1) from Morris Technologies. This part would be impossible to cast but can be easily made through additive manufacturing. Reproduced with permission, Morris Technologies, USA.

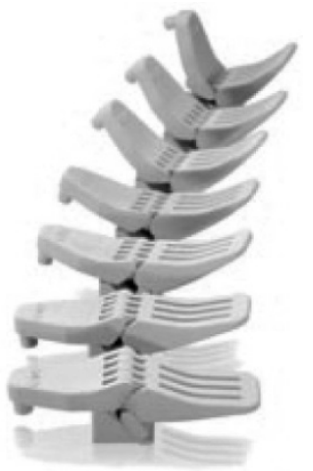

Figure 4. Tie-down clamp made as a single integrated moving component on EOS SLS system. Reproduced with permission, EOS, Germany.

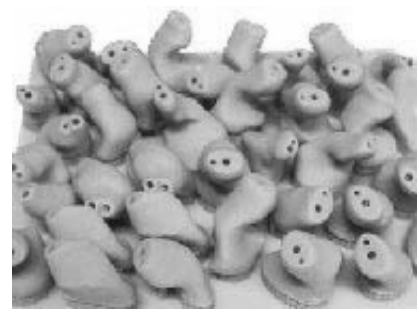

Figure 5. Individually customized hearing aid shells mass-produced by an EOS laser sintering system. Special CAD software has been developed by Materialize to make the process of converting the customers' ear canal laser scan data into the product easy and seamless. Reproduced with permission, The Hearing Review, USA.
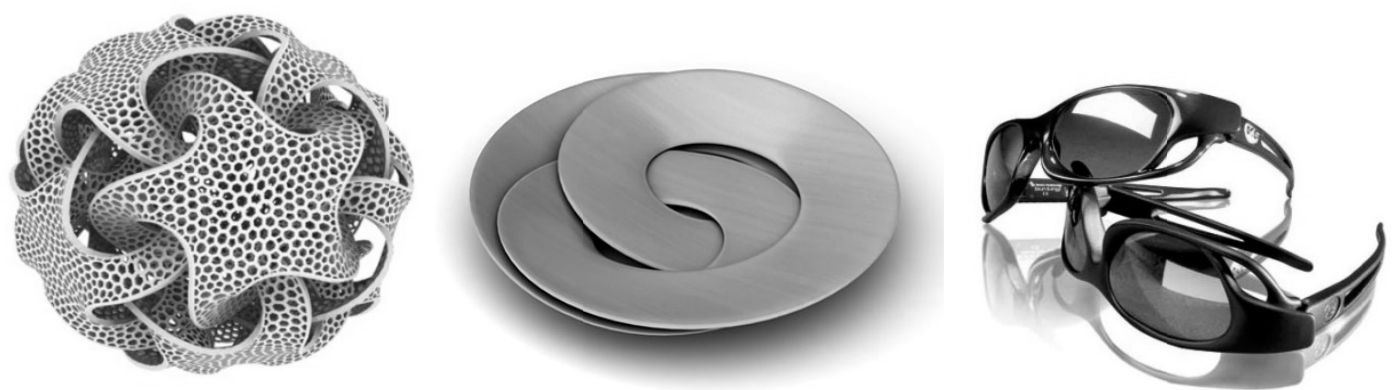

Figure 6. Quintrino lampshade by Bathsheba Grossman (Grossman, 2010), Reproduced with permission, Bathsheba Grossman, Bathsheba Sculpture LLC. Rollercoaster plate by Freedom of Creation (FOC, 2010), Reproduced with permission, Freedom of Creation, Holland, and Treviso Technologia designer sunglasses made for Crabbi Sun Living in production runs of 500 pairs (EOS, 2010d). Reproduced with permission, EOS, Germany. These products were manufactured using selective laser sintering and could not have been cost-effectively made using traditional manufacturing methods. 